\title{
Filón de Alejandría: consideraciones filosófico-políticas en torno a José (patriarca) y la ley de la naturaleza
}

\author{
Philo of Alexandria: Philosophical-political considerations about Joseph \\ (patriarch) and the law of nature
}

\author{
Matías Díaz-Lisboa \\ Estudiante de Licenciatura en Filosofía \\ Universidad de Chile \\ matiasdiaz@ug.uchile.cl \\ Fecha de recepción: 23/04/2020 \\ Fecha de aceptación: 24/07/2020
}

Cómo citar este artículo: M. Díaz-Lisboa. "Filón de Alejandría: consideraciones filosófo-políticas en torno a José (patriarca) y la ley de la naturaleza" en Palabra y Razón. Revista de Teología, Filosofía y Ciencias de la Religión. N $^{\circ} 17$ Julio 2020, pp 26-43 https://doi.org/10.29035/pyr.17.26

Resumen: Inherente al Corpus Philonicum es su aparente desprecio por la vida política, presentada como un velo que sesga nuestra percepción total de la verdad; retrato de lo anterior es la vida de José, que en palabras de Filón es una simple adición del Señor, sometido a la mutabilidad de lo sensible, Egipto. Esta noción, ha sido la interpretación estándar sobre José. No obstante, en este trabajo se mostrará que esta vía negativa no ha sido más que un leve error. Es por ello que se desarrollará una tesis que no enmarque a José bajo las categorías canónicas, como villano para los judíos, o ideal legislador para los romanos, sino que, teniendo como base el concepto de ley natural y sus entrecruzamientos con su hombre de estado, sea considerado bueno tanto para judíos como romanos.

Palabras claves: José / política / ley de la naturaleza / Moisés / recta razón

Abstract: Inherent in the Corpus Philonicum is its apparent contempt for political life, presented as a veil that skews our total perception of truth; a portrait of the above is the life of Joseph, who in the words of Philo is a simple addition of the Lord, subjected to the mutability of the sensible, Egypt. This notion has been the standard interpretation about Joseph. However, in this work it will be shown, that this negative path has been only a slight error. That is why a thesis will be developed that does not frame Joseph under canonical categories, as a villain for the Jews, or an ideal legislator for the Romans, but, based on the concept of natural law and its intersections with his statesman, be considered good for both Jews and Romans.

Keywords: Joseph / politics / law of nature / Moses / right reason 
M. Díaz-Lisboa. "Filón de Alejandría: consideraciones filosófo-políticas en torno a José (patriarca) y la ley de la naturaleza" en Palabra y Razón. Revista de Teología, Filosofía y Ciencias de la Religión. № 17 Julio 2020, pp 26-43 https://doi.org/10.29035/pyr.17.26

\section{Introducción}

Filósofo y erudito judío, Filón, es conocido en su ambiente cultural en primera instancia gracias a su familia ${ }^{1}$, para posteriormente, ser reconocido como un gran maestro de su comunidad. Con aquella fama, es que en el año 38 debe actuar en favor de su pueblo, por las problemáticas que afectaron a los judíos, en lo que se conoce como "the first pogrom". Político por infortunio, es que nuestro autor repercute primeramente en el ámbito social $^{3}$, para posteriormente ser patrimonio de toda la teología y filosofía medieval.

Las directrices básicas la filosofía política filónica, se distribuyen en base a tres clasificaciones establecidas por uno de los grandes comentadores modernos de Filón, Erwin Goodenough, que son: (1) Los textos con perspectivas apologéticas como In Flaccum; (2) aquellos que discuten materias comunes de la forma política, dirigidos esencialmente a otras comunidades como los griegos o romanos y por último (3) los estrictamente esotéricos para su propia comunidad ${ }^{4}$.

Asímismo, tesis central dentro del pensamiento filosófico-político filoniano, es la centralidad de Moisés, que es "characterized basically in terms of the contemporary ideal of the King, who was to be a divine man

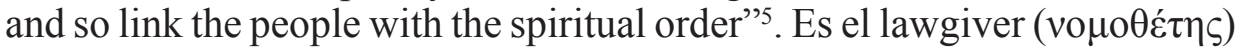
por excelencia, el dador de leyes que capta en primera instancia la ley de la

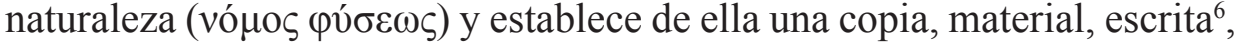
una realidad divina como regalo para la humanidad.

1 Probablemente el segundo hijo de una familia perteneciente a la elite de la diáspora judía, ubicada en Alejandría. Para lo anterior, Seland nos dice "Philo belonged to a rich and influential family in Alexandria [...] Philo thus undoubtedly belonged to the elite segment of the Jewish Alexandrian community. To be rich at this time and in this world also implied power, and power meant influence" T. Seland. "Philo as a Citizen: Homo politicus" en Reading Philo. A Handbook to Philo of Alexandria. Wm. B. Eerdamns Publishing Co.: Cambridge, 2014, pp. 47-74, p.50-51.

2 Saqueo y matanza de gente indefensa, especialmente grupos religiosos, llevados a cabo por una multitud. Lo cual lo llevó a encabezar una embajada en el año 40 ante el emperador Gayo Calígula, testimoniada en su obra "Legatio ad Gaium", con el fin de hacer valer el derecho al culto por parte de los judíos.

3 Para esto, puede verse la temprana referencia que realiza Flavio Josefo en Ant. XVIII. 8, 1. J.

Vara (trad.). Flavio Josefo. Antigüedades Judías. Akal: Madrid, 1997.

4 Sobre esto, ver: Erwin Goodenough. An Introduction to Philo Judaeus. Yale University Press: London, 1940, p. 72-73.

5 E. Goodenough. An Introduction to Philo Judaeus. P.38.

6 Un gran análisis contemporáneo acerca de esta relación, la podemos ver en "The law of nature exists in the realm of the Logos, and is, in some ways, the Logos. This gives it an ontological status somewhat higher than the law of Moses, for the law of Moses, a written law and a law which exists in corruptible nature, is a copy, albeit a true one, of the law of nature." J. Martens. One God, One Law: Philo of Alexandria on the Mosaic and Greco-Roman Law. Brill Academic Publishers: Boston, 2003, p.96. 
M. Díaz-Lisboa. "Filón de Alejandría: consideraciones filosófo-políticas en torno a José (patriarca) y la ley de la naturaleza" en Palabra y Razón. Revista de Teología, Filosofía y Ciencias de la Religión. No 17 Julio 2020, pp 26-43 https://doi.org/10.29035/pyr.17.26

En este punto, ya es pertinente concebir la concepción filosófica que Filón tiene de la política. Al igual que Platón, la ignorancia de los políticos y la inoperancia en términos de sabiduría por parte de la muchedumbre, es un tema recurrente ${ }^{7}$. Con facilidad, uno estaría tentado a afirmar un odio a la política en Filón, al igual como pasa con Platón, pero en estos dos casos no parece ser más que un prejuicio, basta con mencionar que Platón formuló un extenso esquema político en la República, desarrollando un régimen político ideal, mostrando con ello su amor a la correcta política y odio a quien la corrompe. Del mismo modo, Filón escribió alrededor de tres textos solidos de política, el De Iosepho, In Flaccum y De Legatione ad Gaium, en los cuales repasa tanto su participación en la vida política, como el despliegue de una política universal cosmopolita ${ }^{8}$.

Una posible interpretación del texto filónico Spec. 3, 1-69; ha desembocado en un leve prejuicio que desmontaremos en este artículo ${ }^{10}$. Esta interpretación piensa la postura filosófica de Filón, desde una perspectiva negativa, donde permea una leve fobia a todo aquello sometido al devenir temporal, cosa esencial a la política.

En esta anterior referencia (Spec. 3, 1-6), encontramos dos dilemas centrales para nuestros fines; lo primero, son los gustos y disgustos que Filón desarrolla con respecto a la política, y segundo, una pequeña caracterización de la naturaleza de lo político. Filón comienza este tratado, haciendo referencia a su postura personal, su pensamiento y apreciación que tiene de sus gustos e intereses, nos presenta su proyecto de vida

7 La clásica crítica platónica a la democracia es presentada por Filón como un análisis de su

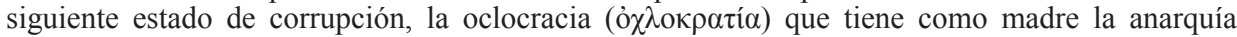

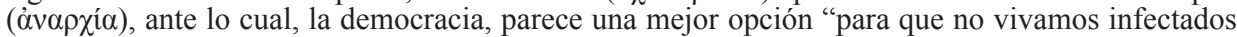
por la oclocracia - el más funesto de los regímenes políticos perversos, que es una adulteración de la democracia perfecta" (Agr. 45).

8 Deuda estoica que posee Filón, considerando al mundo como una gran ciudad, "Finalmente, el mundo sensible es definido como la ciudad universal, según la concepción estoica, la gran cosmópolis, regida por las leyes perfectas de la naturaleza, leyes no meramente mecánicas sino fuentes de moralidad" J. Triviño (trad.). Obras Completas de Filón de Alejandría. Acervo Cultural: Buenos Aires, 1976, p.28. Efectivamente, el cosmos entero es una gran ciudad, que debe ser dirigida

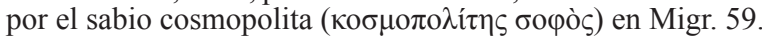

9 Goodenough interpretando Spec. 3, 1-6; y Leg. II, 85; nos dice "As a protest against a life of concern with legal matters the passage has point $[\ldots]$ he represents his life in the crowd as the supreme tragedy of his life" E. Goodenough. The Politics of Philo Judaeus. Practice and Theory. Yale University Press: Boston, 1938, p. 67-68. Lo cual, es una clara interpretación negativa de la visión filosofía sobre la política en Filón, en donde se asocia la multitud de la política a una tragedia que arremete la vida contemplativa.

10 Este prejuicio también ha sido introducido por el análisis de la supuesta intencionalidad subterránea de los escritos filónicos, en especial esto fue formulado por Goodenough, quien ve en aquellos, una especie de propaganda anti romana, esto nos resume bien José Pablo Martín cuando nos dice "No está de acuerdo con este juicio E. Goodenough, que interpreta los escritos históricopolíticos de Filón como panfletos intimidatorios antirromanos, pero varias lecturas posteriores han corregido con buenas razones la visión de Goodenough en este aspecto" J. Martín. Filón de Alejandría Obras Completas. Volumen I. Trotta: Madrid, 2009, p. 74. 
M. Díaz-Lisboa. "Filón de Alejandría: consideraciones filosófo-políticas en torno a José (patriarca) y la ley de la naturaleza" en Palabra y Razón. Revista de Teología, Filosofía y Ciencias de la Religión. No 17 Julio 2020, pp 26-43 https://doi.org/10.29035/pyr.17.26

\section{diciendo}

"Hubo un tiempo, en que libre de otras preocupaciones, me entregaba al estudio de la filosofía y a la contemplación del mundo y de las cosas que él contiene $[\ldots]$ acompañado siempre de divinos asuntos y doctrinas, con los que me sentía dichoso" (Spec. 3, 1)

Parece ser clara la visión de Filón en este asunto, la filosofía se presenta como su vocación, aquello por lo cual es capaz de desplegar sus alas y caminar por los aires, amor adquirido gracias a su formación educacional, en la cual se dedicó al estudio de la paideia griega, pero sin descuidar el fin último de ella, que era la filosofía o búsqueda de la sabiduría, que según Filón es "la ciencia de las cosas divinas y humanas y de sus causas.” (Congr. 79). El texto citado más arriba (Spec. 3, 1) nos habla de un tiempo en el cual él se podía dedicar concretamente a sus intereses y no era arremetido por otras preocupaciones de gran envergadura, podía gastar su vida en su "amor apasionado por el cultivo del saber, enraizado en mi alma desde mis primeros años" (Spec. 3, 4).

Filón nos entrega una descripción de su individualidad ${ }^{12}$, de sus intereses, que no se encuentran en concordancia con lo que posteriormente nos relatará, aunque lo importante por el momento es tener en cuenta que su exposición obedece a sus gustos, ellos son los que están en juego; en este escrito no se encuentra la descripción de lo que un sabio debe amar y odiar, ni de las máximas a las que debe acomodar su vida. Filón no identifica sus propios intereses y vida con el ideal de un hombre sabio.

Ahora, en segundo lugar, ahondaremos en la pequeña caracterización que Filón nos da de la naturaleza de la política, la cual es un "inmenso mar de preocupaciones creadas por los públicos sucesos, en los cuales me veo arrastrado sin poder siquiera mantenerme a flote" (Spec. 3, 3). La política está inmersa en el devenir histórico y muchas veces caótico,

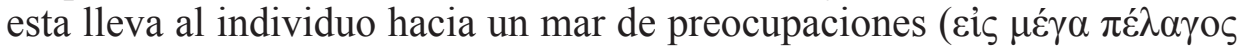

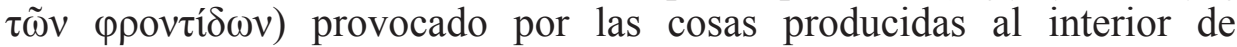
la ciudad ( $\dot{\varepsilon} \vee \pi 0 \lambda \imath \tau \varepsilon i ́ \alpha)$. Esta cruda visión acerca de la política no deja de ser extremadamente verdadera, en el ámbito de la política es que la contemplación divina y estática se ve súbitamente interrumpida, donde de

11 En este caso, la cita es de la edición española de José Triviño, pues la edición de Martín utilizada para todas las anteriores citas no cuenta con todos los tratados filónicos tras quedar incompleta, cosa de la cual la edición de Triviño tampoco se salva.

12 La propia utilización de la primera persona singular griega en este primer párrafo Spec, 3, 1; nos da las coordenadas de una interpretación subjetiva de lo que se hablará, una apreciación individual,

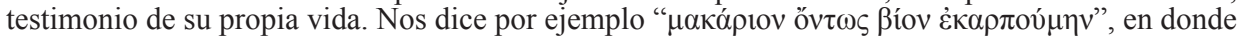
la utilización del verbo "recoger frutos" es en la persona gramatical anteriormente indicada. 
M. Díaz-Lisboa. "Filón de Alejandría: consideraciones filosófo-políticas en torno a José (patriarca) y la ley de la naturaleza" en Palabra y Razón. Revista de Teología, Filosofía y Ciencias de la Religión. No 17 Julio 2020, pp 26-43 https://doi.org/10.29035/pyr.17.26

la unidad se pasa a la multiplicidad, de la tranquilidad a la preocupación.

Si nos quedamos tan solo con este pasaje, es fácil ver en Filón un odio a la política, un resentimiento contra esta vía que lo arranco biográficamente de su mayor anhelo, la contemplación de Dios. Pero si hacemos ello, nos topamos con algunos problemas que pueden ser resueltos con una apreciación panorámica de la política en los textos filonianos. Primero que todo, no hay que olvidar como ya dijimos, que estas anteriores afirmaciones obedecen a los gustos de nuestro autor, permanece en el ámbito de lo meramente subjetivo; incluso esta breve introducción, en el texto no llega a utilizar más que seis párrafos, para posteriormente seguir con la interpretación de las leyes de Moisés.

En el pensamiento filosófico de Filón con respecto a la política, nos salta a la vista de inmediato el aspecto histórico en el cual se encontró nuestro autor y su texto anteriormente revisado; en el cual se relata sin mayores ataques a autoridades de la época, pero de forma directa, el desprecio que le provocó la política de su tiempo. Hay que recordar que el ambiente que Filón vivió cercano a sus últimos años obedece a una polarización provocada entre judíos y romanos, específicamente por las transgresiones al derecho a culto que tenían las comunidades en el imperio y específicamente aquello conocido desde el mundo cristiano como la bancarrota en el terreno religioso de Roma, la gran cantidad de nuevas divinidades, tanto de las familiares, como las estatales, chocaron primariamente de manera fuerte con el mundo hebreo y posteriormente con el cristiano ${ }^{13}$.

Atravesado por estas circunstancias históricas es que Filón nos introduce a su texto (Spec. 3, 1-6), pero no por ello, piensa de esta manera sobre la política. Para Filón la política es una característica de las que ejercita el sabio, aquel ser humano que se apega a la ética de la conducta humana, pues es de la ética que

"se desprenden los géneros de la política, que trata de la ciudad, y de la economía, que trata del cuidado de la casa [...] El sabio, entonces, bajo múltiples nombres y denominaciones, abarca todas estas cosas: piedad, santidad, fisiología, meteorología, ética, política, economía facultad de gobernar y legislativa" (Ebr. 91-92)

13 La propia utilización de la primera persona singular griega en este primer párrafo Spec, 3, 1; nos da las coordenadas de una interpretación subjetiva de lo que se hablará, una apreciación individual,

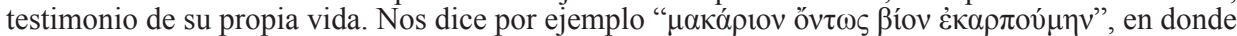
la utilización del verbo "recoger frutos" es en la persona gramatical anteriormente indicada. 
M. Díaz-Lisboa. "Filón de Alejandría: consideraciones filosófo-políticas en torno a José (patriarca) y la ley de la naturaleza" en Palabra y Razón. Revista de Teología, Filosofía y Ciencias de la Religión. № 17 Julio 2020, pp 26-43 https://doi.org/10.29035/pyr.17.26

La política como rama de la ética es indispensable para el sabio, recordando aquella tripartición de la filosofía en lógica, física y ética, es el fruto que se consigue tras obtener un buen terreno (lógica), en donde se pueda desarrollar un buen cultivo (física). Incluso, Filón nos dice que

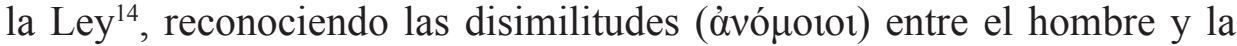
mujer, juzgó sus vidas de manera distinta, al hombre tocándole por suerte la política ${ }^{15}$.

Por todo lo anterior, cabe concluir en este primer momento, que Filón nunca dudo de la importancia de la política ${ }^{16}$, es algo obligatorio dentro de las cualidades de un sabio. La política parece ser una perversión solo en lo que podemos llamar "los errores de la política romana"17. Generalmente cuando Filón juzga la política como forma velada de la verdad, está haciendo referencia a las formas que esta adoptó en determinadas ocasiones de la administración romana, como por ejemplo cuando se aludirá a los ataques contra los judíos ocasionados por la política antisemita de Seyano en Flacc. 1-2; o cuando hablando sobre los efectos que produce el vino en las personas, menciona dos, uno bueno en donde las agitaciones del espíritu se serenan y la otra mala donde se asemeja "a un vendaval violento e intenso, a un mar en tempestad y oleaje o a una sublevación" (Somn. 2, 166), una sublevación con tintes políticos, la cual recuerda vivamente a la arremetida contra los judíos.

\section{José como problema}

14 Haciendo referencia a la ley escrita (material) por Moisés, que es la sagrada escritura (ó i̊pò $\varsigma$

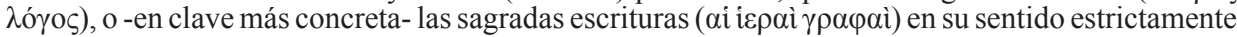
de leyes (vouoí) escritas por Moisés. Establezco esta diferencia, pues la primera denominación (ó ípòs $\lambda$ ó $\gamma \circ \varsigma$ ), que en los textos de Filón introduce a lo que hoy denominamos libros sagrados, tiende abarcar un campo semántico mucho más grande que la sola materialidad de la Torá o Tanaj.

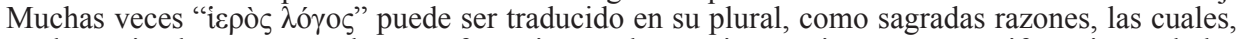
en determinados contextos hacen referencia no a las escrituras, sino que, a manifestaciones de las potencias de Dios, como es el caso de los ángeles. Un ejemplo claro es "Todo el pueblo, jóvenes y viejos, al mismo tiempo, rodearon la casa, en conjuración contra los divinos y sagrados discursos, a los que habitualmente llamamos ángeles" (Conf. 28), lo cual llevará a afirmar por parte de Filón, que estos discursos o palabras son las que guían al hombre hacia Dios y a los cuales comúnmente se les denomina ángeles (Migr. 173), lo cual no es precisamente la Ley escrita que Moisés nos otorgó.

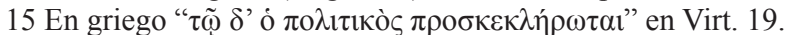

16 Que la política este restringida a la naturaleza del hombre, entendido en su sentido específico de varón (ג่ví $\rho$ ), ya nos dice mucho, pues en Filón el hombre es superior a la mujer, esta última está ligada a los placeres corporales, en cambio el hombre está emparentado con la naturaleza divina; misma distinción que establece entre el padre y la madre, siendo el primero el intelecto que debe actuar como rector y la madre como la parte del alma ligada a los sentidos. En este sentido vemos claramente como se aparta de Platón en su lectura filosófica-política, para Platón hombres y mujeres podían participar de las mismas clases dentro de la república.

17 No por haber presentado errores esta política, podemos concluir con Goodenough que Filón era un antirromano, la conclusión a la que llega José Martín en este punto me parece muy aclaratoria, "Filón manifiesta ante Calígula la nostalgia de la pax romana, y no se trata de simulación, sino de ideología [...] Augusto es el reflejo de la monarchia que se debe solo a Dios (Legat. 149)" J. Martín. Filón de Alejandría. P.74. 
M. Díaz-Lisboa. "Filón de Alejandría: consideraciones filosófo-políticas en torno a José (patriarca) y la ley de la naturaleza" en Palabra y Razón. Revista de Teología, Filosofía y Ciencias de la Religión. No 17 Julio 2020, pp 26-43 https://doi.org/10.29035/pyr.17.26

Después de la anterior introducción a la visión política de Filón, entraremos de fondo en la problemática central de este trabajo. Primero ver cuales son los dilemas que atraviesan la concepción filónica sobre José el patriarca como hombre de estado y político por naturaleza, para posteriormente en el siguiente apartado, desmitificar algunas nociones adjudicadas a José, sobre todo teniendo como base, el problema ya presentado e introducido por Goodenough, pero que ahora se respalda en una caracterización específica de José.

Aquella caracterización positiva con la cual concluimos el apartado introductorio se verá interrumpida aquí por un personaje bíblico que generó controversias, José el patriarca. Muchas veces dentro del Corpus Philonicum, las referencias y caracterizaciones que se hacen de este personaje suelen ser contradictorias, es presentado como quien practica la cuarta vía de la excelencia ${ }^{18}$, o como quien es vendido a muchos amos ${ }^{19}$, símbolo del político que se vende para poder ejercer su cargo. José parece no haber tenido un prospero camino, es el hermano que fue vendido a unos mercaderes que, se dirigían al lugar de las pasiones corporales, Egipto ${ }^{20}$, es comprado y pasa a ser su amo un eunuco, cosa que no deja de ser importante, pues el eunuco "parece tener los órganos de la reproducción, aunque carece del poder reproducirse [...] incapaces de crear sabiduría, aunque parezcan practicar la virtud" (Jos. 58-59). José tiene como dueño al eunuco que al igual que la multitud, es incapaz de la sabiduría, José

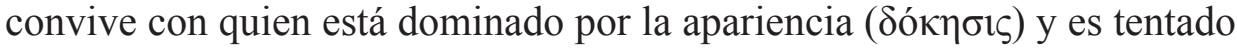
por su mujer, que alegóricamente significa la pasión que convive con la muchedumbre (el eunuco), José en definitiva se encuentra y experimenta Egipto.

Sobre José recaen la mayoría de las referencias negativas, lo político aparece como un adicional a la naturaleza y su virtud, esto se le reprochara a José, el haber hallado su abundancia en lo exterior, no poder permanecer en la magnificencia de Dios y arrastrado por lo político, permanecer en ello (lo político); ser joven con respecto a la madurez del alma, como lo llama Jacob (Sobr., III, 12). José es el ho mepo dynamenos, el que 'aún no puede', aún no puede salir de su fundamentación relativa a lo corporal y a

18 En la obra de Filón, cada patriarca (Abraham, Isaac y Jacob) representa una virtud específica o forma de vida perfecta, según el aprendizaje, la naturaleza y la ascética. En este caso, José representa a la cuarta forma de vida excelente, la política (Jos. 1).

19 En Jos. 35-36; José es presentado como un esclavo sometido a muchos amos, inmerso en el mar de la multitud, pues tiene "un carácter caprichoso y amante de cambio" (Jos. 36).

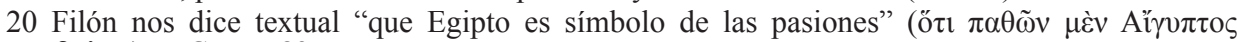
$\sigma u ́ \mu \beta 0 \lambda o ́ v)$ en Congr. 83. 
M. Díaz-Lisboa. "Filón de Alejandría: consideraciones filosófo-políticas en torno a José (patriarca) y la ley de la naturaleza" en Palabra y Razón. Revista de Teología, Filosofía y Ciencias de la Religión. No 17 Julio 2020, pp 26-43 https://doi.org/10.29035/pyr.17.26

las opiniones propias de la sofística. ${ }^{21}$

En torno a esto que acabamos de presentar, es que surgen las dudas que acogieron algunos comentadores de la obra de nuestro autor, intentando dar respuesta a estas contradicciones evidentes dentro de la interpretación correspondiente a José el patriarca. Por ejemplo, de si lleva este o no, una vida excelente y acorde a la virtud; y si, siendo un político, podemos considerar la política como algo bueno para el alma que la ejercita, o solo contribuye en corromper a quien está inmerso dentro de ella.

La solución principal que se ha elaborado sobre esto es la dada por Goodenough y repetida muchas veces por los comentadores, en la cual se ven los textos de Filón desde diferentes interlocutores y que según ya mencionamos, pueden ser textos en clave que puedan entender tan solo judíos, o algunos que, de manera más universal puedan ser entendidos por todos y en específico como interlocutor ideal el romano. En cualquiera de las dos formas, la tendencia principal o lo que ocultarían estas aparentes contradicciones, es un odio por los romanos, donde José aparece como un salvavidas de la política, en donde siendo un político judío, puede gobernar al pueblo extraño (Egipto), lo cual sería una referencia dirigida a los romanos, con el fin de introducir la idea que la política judía encarnada en el José de Egipto, puede funcionar para los judíos en la Roma contemporánea a Filón.

Goodenough así, trata la figura de José en 'The politics of Philo Judaeus' en el tercer capítulo, el cual tiene por nombre 'Politics by innuendo' que puede ser traducido por "política por insinuación". Goodenough ya presentó en el primer capítulo la figura de Filón como un político de su comunidad, cosa hoy en día y ya desde antiguo, muy interesante, pues nos muestra el contexto judío ante el quiebre con la autoridad y nos presenta como se organizaban los judíos en esos tiempos, cuáles eran sus derechos que Filón reclama y la legitimidad de sus organizaciones como la politeuma autónoma dentro de una ciudad o su propio senado llamado gerousía. Ahora en este capítulo, se analiza la figura de José a lo largo de la totalidad del tratado De Iosepho, en él se desarrollan los interlocutores supuestos, en conjunto con una profundización del texto mismo, con el fin de evidenciar su perfil humano, por ejemplo, como modelo de lo

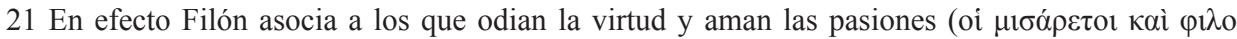
$\pi \alpha \theta \varepsilon i \bar{\varsigma})$ con un uso indebido del lenguaje, que es el propio de los sofistas que "usan el lenguaje como aliado para introducir sus doctrinas reprobables" (Conf. 34), cosa similar a la que dice del lenguaje de José, "Pues, también en un llano, es decir, en una lucha de palabras es hallado errante José, el promotor de una doctrina abigarrada más útil para el carácter de a política que de la verdad" (Det. 28). 
M. Díaz-Lisboa. "Filón de Alejandría: consideraciones filosófo-políticas en torno a José (patriarca) y la ley de la naturaleza" en Palabra y Razón. Revista de Teología, Filosofía y Ciencias de la Religión. No 17 Julio 2020, pp 26-43 https://doi.org/10.29035/pyr.17.26

que es el prefecto romano ${ }^{22}$, el político ideal o representando las faltas a las que tienden los romanos en sus gobiernos, y como estas pueden ser identificadas en el personaje de José, con el fin de que sean reparadas las políticas o conductas injusta por parte de lo romanos.

La posición de Goodenough se puede resumir en lo que el mismo dice "It is my conviction that the entire allegory of Joseph is a clever piece of double entendre, a fierce denunciation of the roman character and oppression" 23 . Con esta propuesta, Goodenough nos presenta a José como el prefecto romano, siendo característico de él tres aspectos negativos: (1)

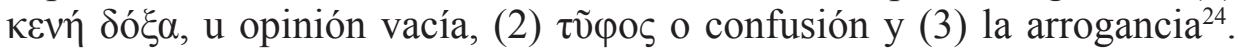
Así, con esta caracterización de José, se marcan sus aspectos negativos que el mismo Filón critica, como lo podemos ver en:

El nombre de José no testimonia menos su preferencia y celo por la vida. Pues José significa adición. La vanagloria añade siempre a lo auténtico lo ilegítimo... ${ }^{25}$

Esta interpretación de Goodenough con respecto al carácter negativo que Filón quiere expresar sobre José no deja de ser cierta, pero ha de ser analizada en perspectiva. Claro es que José parece ser en el comienzo del escrito dedicado a su persona, un error dentro del ser humano, José parece manifestar los errores en los que el ser humano cae continuamente por su falta de madurez. Pero si uno analiza la secuencia del mismo texto, se percata que este, progresa en una exaltación del crecimiento espiritual de José. Cuando él pasa de la casa de su padre, a ser esclavo del eunuco, Filón cree que ya está preparando su prospero camino, pues este paso por la casa del eunuco significó alegóricamente un desarrollo de José en la economía y administración de la casa, para posteriormente y con experiencia, poder gobernar la gran casa en la que nos encontramos, que es este mundo. El paso por la casa del eunuco significó para José, la adquisición de la experiencia micropolítica con vistas a lo que posteriormente se vendrá en el desarrollo bíblico del personaje. El propio Filón lo expresa en estos términos

"Pues era necesario que, el que iba a convertirse en político, se ejercitara y practicara primero la administración doméstica, pues una casa es una ciudad de dimensiones reducidas y la administración doméstica

22 Goodenough mismo lo dice en su presentación "the next incident from the life of Joseph brings out another of the characteristics of the ideal king or governor." E. Goodenough. Politics of Philo, p.52.

23 E. Goodenough. Politics of Philo, p. 21.

24 Recogido de T. Seland. "Philo as a Citizen", p. 59.

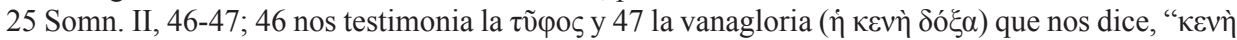

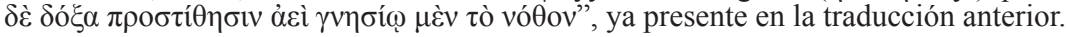


M. Díaz-Lisboa. "Filón de Alejandría: consideraciones filosófo-políticas en torno a José (patriarca) y la ley de la naturaleza" en Palabra y Razón. Revista de Teología, Filosofía y Ciencias de la Religión. $\mathrm{N}^{\circ} 17$ Julio 2020, pp 26-43 https://doi.org/10.29035/pyr.17.26

es una especie de política, de manera que la ciudad es una gran casa y la política es la administración de la comunidad" (Jos. 38)

Estos rasgos, combaten con aquella descripción negativa que nos daba Goodenough con el fin de argumentar un Filón antirromano. Filón más bien quiere presentar ejemplos, en primera instancia, de los errores a los que se enfrenta y cae un político en sus comienzos de su gobierno, pero que después en una segunda instancia, es capaz de superar, con vistas a ejercer en completitud la virtuosidad de su cargo.

José, como vemos en la cita anterior, pasó y seguirá pasando a lo largo de los escritos de Filón, por diferentes pruebas que le permitirán un desarrollo espiritual específico y necesario para un político, en este primer ejemplo es la necesidad en la experiencia del cuidado y gobierno de la casa, como símbolo de lo que será una ciudad; posteriormente se desarrollarán pruebas como la de ser un modelo de virtud en la prisión, otras como, las relaciones entre el gobernante e interprete de sueños, culminando con las bellas palabras de Filón que corroboran mi exposición, que dicen "de su sentido común la sencillez con que se desenvolvió en las inenarrables desgracias de su vida, que convirtió lo inarmónico en armonía y lo discordante por naturaleza en orden" (Jos. 269). José no oculta ni simboliza un odio a lo romano, sino que más bien expresa el camino de la vida política que, siendo un añadido del Señor, no deja de ser una virtud necesaria para el sabio, la cual se debe ejercitar para poder aspirar a la cumbre que se ve reflejada en el final del escrito de Filón, en José el patriarca, el homo politicus por excelencia.

Con todo lo anterior, se evidencia el leve error en la interpretación de la política inherente a José, como punto para demostrar una política de odio hacia los romanos. Que José haya sido tomado alegóricamente como un prefecto romano, pues sus errores calzaban con las actitudes de soberbia que tenían los romanos en esos tiempos, no termina de ser una argumentación concluyente, pues arrastra en su argumento un odio subterráneo antirromano y antipolítico, que en los escritos no parece evidente, pues como ya expusimos brevemente en la introducción, de las pocas veces que Filón reclama contra la política, no lo hace por su propia naturaleza, sino por sus propios gustos, no es una crítica filosófica en algún sentido, sino que meramente biográfica por las situaciones a las que se vio arrastrado Filón ${ }^{26}$.

26 Inclusive Goodenough llega a esta conclusion "As it stands, the passage is a cry against his having had to abandon a life of contemplation in order to devote himself to political matters." E. Goodenough. Politics of Philo, p. 66. 
M. Díaz-Lisboa. "Filón de Alejandría: consideraciones filosófo-políticas en torno a José (patriarca) y la ley de la naturaleza" en Palabra y Razón. Revista de Teología, Filosofía y Ciencias de la Religión. № 17 Julio 2020, pp 26-43 https://doi.org/10.29035/pyr.17.26

Mi crítica a la interpretación alegórica que llega Goodenough no es nueva, ya ha sido puesta en duda por varios autores contemporáneos, por ejemplo, Maren Niehoff nos dice "Philo's family background, wealth and education perfectly qualified him for such position. He was virtually predestined for a distinctly pro Roman position"27, lo cual entra en directa contradicción con el postulado de Goodenough. Filón probablemente estuvo a favor del gobierno romano, lo cual no ocasiono un seguimiento ciego de sus políticas, sino que, por el contrario, llego a plantear varias críticas a este durante su vida, sin olvidar su propia identidad judía que debía proteger con los romanos y la propia tranquilidad de su pueblo que debía propiciar con los gobernantes. El fin de todo esto, era mantener gracias a sus vínculos con estas dos cosmovisiones, la tranquilidad en Roma, evitando posibles sublevaciones, a la vez manteniendo a salvo las características propias de su pueblo, ante posibles irrupciones arbitrarias provocadas por gobernantes inexpertos.

\section{José y la ley de la naturaleza}

Después de haber desmontado esos pequeños prejuicios que versan sobre la obra de Filón y con ello sobre José, cabe presentar realmente y sin el velo antirromano, aquello a lo que realmente esta representando José el patriarca, lo que algunos como Clara Kraus Reggiani ${ }^{28}$ llama una doble ciudadanía, que será enmarcada dentro del proyecto de una ciudadanía universal, desde los aportes que aquí presentaremos y que ya han sido adelantado durante la obra. Estos son, el análisis de la política de José como una política universalista, en la madurez de este personaje, el cual logra alcanzar este ideal, gracias a su relación con la ley de la naturaleza, que muchas veces se presenta como el Logos divino.

27 M. Niehoff. "Jewish Identity and Jewish Mothers: Who was a Jew According to Philo?" en The Studia Philonica Annual. 11/1 (1999), pp. 31-54, p. 39-40. En las mismas páginas, en la nota 34, realiza un resumen de los autores que han estado ha favor de la tesis de Goodenough y aquellos que actualmente, han juzgado como inapropiada esta tesis. Lo mismo nos dice Seland cuando termina su exposición sobre la política que representa José, en la cual reutiliza las mismas categorías de Goodenough, concluye con que esta interpretación ha sido puesta en duda, nos dice "Goodenough's allegorical readings have not found universal approval, several scholars finding them too subtle to be obvious to the first readers. Also debatable is whether Philo, coming from a family so close to the Romans, could have cherished such negative attitudes towards the Romans." T. Seland. "Philo as a Citizen", p. 60.

28 En general la visión de Goodenough ha sido criticada como ya hemos visto, por no ser concluyente y suponer demasiadas cosas dentro la alegoría filoniana. Clara Reggiani nos dice sobre esto "L'intera disquisizione, dottissima e ampiamente documentata, ha i caratteri di un vero e proprio paralogismo per l'infondatezza delle postulazioni di fondo, proposte come altrettanti dati obiettivi, laddove sono il frutto di una lettura in chiave politica strettamente personale." K. Reggiani. "I rapporti tra l'impero romano e il mondo ebraico al tempo di Caligola secondo la Legatio ad Gaium di Filone Alessandrino" en W. Hasse (ed.), ANRW II, 21, 1. Religion (Hellenistisches Judentum in römischer Zeit: Philon und Josephus). De Gruyter: Berlin, 1984, pp. 555-586, p.582. La erudita italiana, interpreta el análisis de Goodenough como una mera interpretación propia, dotada de mucho contenido. 
M. Díaz-Lisboa. "Filón de Alejandría: consideraciones filosófo-políticas en torno a José (patriarca) y la ley de la naturaleza" en Palabra y Razón. Revista de Teología, Filosofía y Ciencias de la Religión. $\mathrm{N}^{\circ} 17$ Julio 2020, pp 26-43 https://doi.org/10.29035/pyr.17.26

En específico en torno al tema de los supuestos interlocutores, el tratado De Iosepho supondría un lector griego, al cual se intenta convencer de las cualidades de un judío para gobernar, entrando en contradicción específica con otros tratados como el De Somniis, en el que la figura de José según Goodenough es presentada más como una encarnación de lo que Filón querría denunciar, las irregularidades de la política y en específico de la política romana. En este apartado final, veremos como la anterior tesis se cae, pues si uno mira los tratados y la vida de José en perspectiva, no intentan denunciar nada sobre la política específica del momento, sino que más bien, quieren retratar el progreso vivencial y sapiencial de José, se quieren mostrar las peripecias de la vida política.

José fue educado desde muy temprano en lo que Filón llama las artes

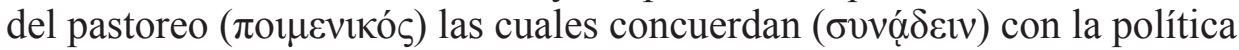

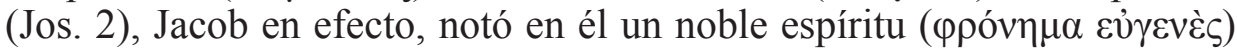
lo cual lo llevo a admirarlo y amarlo más que a sus otros hermanos. Es por ello, que nació la envidia en los demás hermanos, que al igual que la que acecho la vida de Filón, lo arrastró al principio de grandes males, el paso por Egipto y todo lo que en lenguaje simbólico representa la relación con los sentidos y pasiones del cuerpo; pero como dice Filón "Este camino resultó ser el principio de grandes males, aunque también de grandes bienes" (Jos. 12), grandes males por el mar de regímenes diferentes a lo que se iba ver enfrenta, pues "En unas ciudades se han inventado y añadido unas costumbres y leyes y en otras, otras." (Jos. 30); pero también de grandes bienes, pues al final de la narración, José gobernaría Egipto "como si fuera una sola casa, y con él, otros países y naciones azotados por el hambre, de manera tan excelente que no puede describirse con palabras" (Jos. 259).

José será llevado a la casa del eunuco, en la cual, gracias a sus dotes de nobleza, será puesto al frente de ella. Por su gran reputación en el cuidado de la casa (oíkov́pı $\alpha$ ), es que se vio codiciado por los deseos sexuales de la mujer de su amo, siendo juzgado por él a ser prisionero, sin tener la posibilidad de defenderse ante su condenación. Una vez más y ahora en la cárcel, logró demostrar su virtud "que hasta los malvados que allí había estaban asombrados y maravillados" (Jos. 80), José no fue como la mayoría de los carceleros, que conviviendo con los malvados adoptaban sus costumbres, sino que convirtió ese lugar en una escuela de templanza

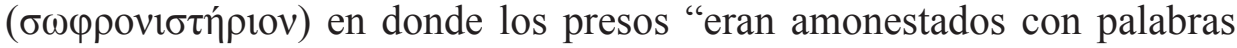
y doctrinas filosóficas y con las conductas de su maestro, más eficaces que cualquier palabra" (Jos. 86). En su estancia encarcelado es que logró interpretar los sueños de dos eunucos que, gracias a su efectividad en el 
M. Díaz-Lisboa. "Filón de Alejandría: consideraciones filosófo-políticas en torno a José (patriarca) y la ley de la naturaleza" en Palabra y Razón. Revista de Teología, Filosofía y Ciencias de la Religión. No 17 Julio 2020, pp 26-43 https://doi.org/10.29035/pyr.17.26

dictamen lo llevó a interpretar los sueños del Faraón y convertirse por mandato de este, en un gobernador de Egipto. La posterior narración de la vida de José ya parece estar dentro del imaginario habitual de las personas, que sería, la administración de los recursos, el encuentro con sus hermanos, el dilema con ellos y la posterior reconciliación, el encuentro con su padre y la muerte de este, por lo cual tan solo quedará enunciado, ahora más bien, es conveniente establecer los lazos que existen entre la narración de nuestro personaje con la ley de la naturaleza.

Pero antes que ello, conviene realizar una digresión para introducirnos en que es la ley de la naturaleza o vó $\mu$ os $\varphi v ́ \sigma \varepsilon \omega \varsigma$. Este concepto no es propio de Filón, ya se encontraba en escuelas anteriores como la de los estoicos. Ley de la naturaleza es una frase que para muchos puede sonar extraña, pues junta la ley (vó $\mu \circ)$ que muchas veces puede ser entendida en su sentido moderno como ley positiva, o aquel mandato que obedece a una convención, en su mayoría democrática, con el fin de ordenarse al bien común de una nación; y contiene también la noción de naturaleza ( $(v \mathbf{\sigma ı \varsigma )}$ ) la cual suele aludir a algo determinado anterior a toda convención $\mathrm{y}$ con validez universal ${ }^{29}$. Parece ser que la primera sistematización de la unión de estos dos aparentes contradictorios, solo vendría con los estoicos, los cuales colocaron en concordancia la ley, la cual es captada por la recta razón (ő $\rho$ os $\lambda$ ó $\gamma \circ \varsigma$ ) y se encontraría inherente en su orden, a la ley eterna o razón universal, el Logos inmanente que rige todo el cosmos.

La ley de la naturaleza también es presentada así por Filón, pero para comprenderla, primero es necesario explicar su teoría del Logos, la cual como es sabido, es muy compleja. El Logos divino es un mediador completamente divino entre el Existente ( $\tau$ ò öv) y los hijos de la tierra que permanecen en la irracionalidad de la carne ${ }^{30}$, el Logos es el fronterizo

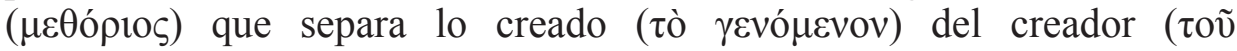

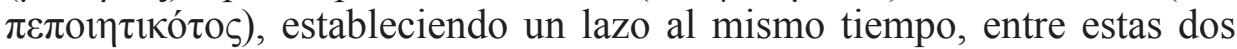
realidades, uniendo todas las cosas (Fug.111). El Logos también es un vínculo $(\delta \varepsilon \sigma \mu o ́ s)$ que mantiene a todo lo creado, permitiendo que las cosas se unan pero que no se mezclen en un mero caos. El Logos tiene una doble función en su carácter de mediador, es trascendente, es el Logos de Dios (ó

29 Esto nos lo resume Martens diciendo "The law of nature would have been considered a "jarring" phrase, even contradictory. It was the bringing together of opposites, and not only in the eyes of the Sophists. J. Martens. One God, One Law, p. 19.

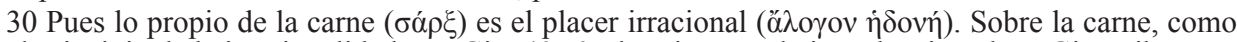
el principio de la irracionalidad, ver Gig. 40; 65, lo mismo en la introducción al De Gigantibus nos dice Radice (2005) "è la carne - osserva l'Alessandrino - il vero principio dell'ignoranza, ed è ancora essa ad impedire che la sapienza abiti in noi stabilmente. Parrebbe una necessità ontológica, ma è anche una questione morale, perchè le passioni della carne inchiodano l'uomo a terra e gli impediscono la visione del cielo" R. Radice - G. Reale (trad.). Filone di Alessandria. Tutti i Trattati del Commentario Allegorico allá Bibbia. Bompiani: Milano, 2005, p. 637. 
M. Díaz-Lisboa. "Filón de Alejandría: consideraciones filosófo-políticas en torno a José (patriarca) y la ley de la naturaleza" en Palabra y Razón. Revista de Teología, Filosofía y Ciencias de la Religión. No 17 Julio 2020, pp 26-43 https://doi.org/10.29035/pyr.17.26

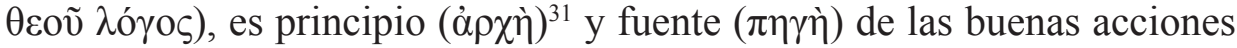

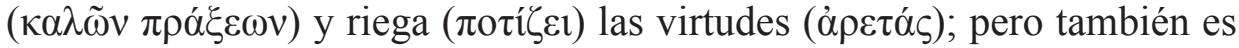
un Logos inmanente, presentado como el principio rector del mundo ${ }^{32}$, lo

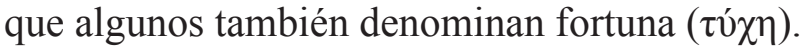

Sobre este Logos inmanente nos dirá John Dillon "Since for him Nature is the logos of God in action in the world, living in conformity with Nature is simply following God"33, el Logos se expresa como naturaleza, lo que es trascendente se presenta ante el mundo como inmanente en el concepto de naturaleza, lo cual entra en plena relación con lo que anteriormente estábamos hablando, pues también en Filón la razón universal, el Logos inmanente, se expresa como naturaleza ( $\varphi v ́ \sigma ı)$ ), que siendo creación de Dios opera según leyes físicas y éticas que Dios nos entregó de manera inalterable ${ }^{34}$, lo cual no deja de ser una definición exacta de lo que es la ley natural. Hay en el ámbito de los intermediarios de Filón un paso del Logos a la physis y de la physis a la ley de la naturaleza, los cuales expresan el camino de Dios hacia los hombres y viceversa, estos intermediarios cubren el abismo entre estas distintas realidades, y son como un sello que dejo el Creador en su creación, que permiten tanto la intervención divina, como la deificación humana.

Por último, estas leyes naturales no son simplemente las leyes de la ciencia, sino que siendo leyes que gobiernan la physis, también gobiernan los cuerpos mortales de los seres humanos, fijando patrones ideales de comportamiento, que se resumen en un conjunto de leyes éticas y sus correspondientes virtudes ${ }^{35}$.

En este punto cabe volver a nuestro querido José, pues si recordamos, él es quien fue enseñado desde la edad de diecisiete años en los asuntos políticos, es el homo politicus por excelencia, que adquiere gran importancia en estos momentos, pues si este mundo es una gran ciudad ( $\left.\mu \varepsilon \gamma \alpha \lambda{ }^{\circ} \pi \mathrm{o} \lambda 1 \varsigma\right)$, ha de estar regida por una única ley (vó $\mu \omega$ \&̇ví $)^{36}$, que según continúa la

31 Todo esto en Post. 127. En Her. 116, también nos dice que el principio es la mitad del todo.

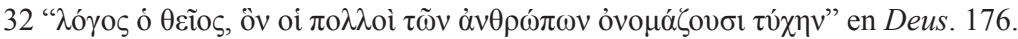

33 J. Dillon. The Middle Platonists. Cornell University Press: New York, 1996, p. 146.

34 Esto nos los dice Martens en el comienzo de su análisis de la ley natural en Filón "Nature is the creation of God. It operates according to certain laws and ordinances, both physical and ethical, which God gave as unalterable (Opif. 61)" J. Martens. One God One Law, p. 83.

35 Najman introduciéndonos a la universalidad de la ley natural, nos dice "Relatedly, Philo emphasized the connection between the law of Moses and the virtues (Mos. 2, 9-11)" H. Najman. "The Law of Nature and The Authority of Mosaic Law" en The Studia Philonica Annual. 11/1 (1999), pp. 55-73, p. 57. No hay que olvidar que la ley de Moisés es una copia de la ley de la naturaleza, con lo cual equivale a decir que, la ley de la naturaleza tiene una relación con las virtudes.

36 En Jos. 29. 
M. Díaz-Lisboa. "Filón de Alejandría: consideraciones filosófo-políticas en torno a José (patriarca) y la ley de la naturaleza" en Palabra y Razón. Revista de Teología, Filosofía y Ciencias de la Religión. No 17 Julio 2020, pp 26-43 https://doi.org/10.29035/pyr.17.26

misma cita, nos dice que es el logos (la razón) de la naturaleza ${ }^{37}$.

Estos textos recientemente citados son de gran importancia, pues puntualizan el alcance al que debe estar sometido la ley natural, la cual permea todo lo existente en el cosmos y preeminentemente aquí, la política misma, pues en ella se presenta como la correcta rectora de todo régimen político, es por ella que las comunidades llegan a acuerdo y se vuelven más virtuosas, y en este punto es que José resalta como un político, pues al ser el político un agregado del Señor, al igual como las leyes son un agregado de la recta razón, el político es un agregado que debe vivir acorde a la naturaleza ${ }^{38}$, por su propia proveniencia divina.

La política, no por ello, permanece en la mera unidad; rasgo característico de esta, es que es complicada y multiforme, como el manto de muchos colores de José. El ejercicio de la política es como dirigir una nave, la cual debe cambiar según los vientos que encuentre, o como un médico que no atiende de la misma manera a todo paciente, incluso ni al mismo de la misma manera, pues debe acomodarse al tipo de dolencia que quiere sanar. La política no es una e invariable como la ley de la naturaleza; entre estas dos vemos un gran vacío, difícil de unir a la fuerza. Como en la mayoría de los asuntos filonianos, quien resolverá el dilema será un intermediario, que en este caso es José, quien es elegido por la naturaleza ${ }^{39}$, que estando en relación con la ley natural y con ello lo divino, es capaz de sortear de buena manera las dificultades inherentes a las diferencias entre pueblos y comunidades, pues este logrará considerar a cada pueblo no por separado, sino como una totalidad, o en palabras de Filón "Pues este mundo es una gran ciudad y necesita una sola forma de gobierno y una única ley" (Jos. 29), una forma de gobierno que adquirió José.

José es un virtuoso que pasó por el pastoreo, el gobierno de la casa y la firmeza, tres características que Filón menciona como necesarias para

37 La gran ciudad que es este mundo necesita de una sola ley, que es la ley de la naturaleza, pero que en la realidad las ciudades no han respetado, pues es por "la ambición y desconfianza mutua, por las que no se contentan con las leyes de la naturaleza (

$38 \mathrm{El}$ texto en griego aquí es magnífico, pues nos presenta las relaciones directas de lo que aquí quiero mostrar, que es, la importancia de la ley natural y como esta ley natural se encuentra en directa concordancia con el político que debe vivir acorde a ellas. En efecto dice " $\pi \rho \circ \sigma \theta \tilde{\eta} \kappa \alpha 1 \mu \grave{\varepsilon} v$

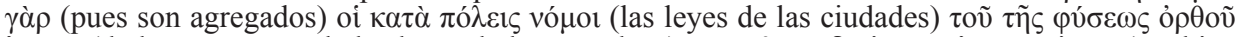

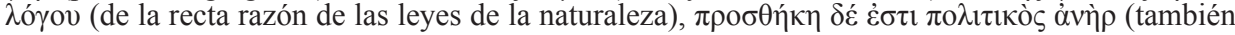

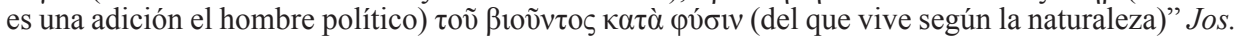
31. Presenta el texto una similitud entre estos dos agregados en tanto agregados que comparten su modalidad.

39 Que sea colocado por la naturaleza en el gobierno de la casa del eunuco, lo cual simboliza el gobierno microeconómico como preparación para la ciudad, es textual en el comentario de Filón,

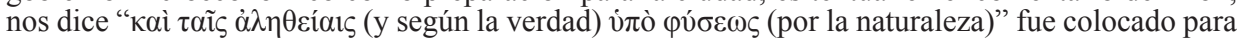
el cargo, en Jos. 38. 
M. Díaz-Lisboa. "Filón de Alejandría: consideraciones filosófo-políticas en torno a José (patriarca) y la ley de la naturaleza" en Palabra y Razón. Revista de Teología, Filosofía y Ciencias de la Religión. No 17 Julio 2020, pp 26-43 https://doi.org/10.29035/pyr.17.26

un buen gobernante (Jos. 54). La falta de virtudes en antiguos políticos generó destrucciones, por ejemplo, entre griegos y bárbaros, y es por ello que el político debe manejar en este caso la virtud de la continencia

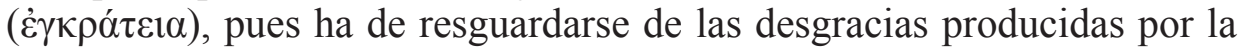
falta de ella (Jos. 54). El político debe ser como un médico (Jos. 63), pues debe administrar curaciones que parezcan no agradables, pero que se rigen según la ley de la naturaleza, encausando a cada uno según la justicia que es capaz de aceptar, el político no es como el cocinero que piensa en los apetitos del presente y como saciarlos, sino que se fija en la "salvación y seguridad de la comunidad" (Jos. 63), piensa en el futura de esta gran ciudad que habitamos.

Por último, el político es como un intérprete de sueños, pues reconoce los mensajes divinos $(\theta \varepsilon i \tilde{\alpha} \alpha \text { ó } \gamma 1 \alpha)^{40}$ que hay en ellos, interpretando correctamente el gran sueño universal que es la vida de los hombres ${ }^{41}$. La vida del ser humano no es más que vanas creaciones mentales que se creen como reales, bellezas que se ven como reales un día y al otro no, cosas efímeras como el paso del tiempo, jóvenes que ya no serán jóvenes $\mathrm{y}$ adultos que ya no son todo lo que fueron, esto es la vida, un mar de inseguridades materiales que fluyen constantemente y que no se quedan en ningún momento. El sueño es la confusa y mutable vida, el sueño es tanto el inconsciente, como aquel que experimentamos día a día en nuestro estado de despiertos y este sueño en general es el que deberá interpretar el político

"con sugerencias razonables y suave persuasión, enseñarles sobre cada uno de estos cuál es bello [...] lo que es prudente, lo que es valiente, lo que es pío, lo que es sagrado, lo que conviene, lo provechoso y, por otro lado, lo que no es provechoso, lo irracional" Jos. 143

El político es el encargado de dotar a este sueño que conocemos por realidad, de patrones que lo dividan, de virtudes que establezcan límites, en general de traspasar a la realidad aspectos racionales de comportamiento, gracias a su propia relación con la naturaleza o ley natural. Al igual que el Logos que media entre las cosas y también las une, el político estará encargado de interpretar la confusión del mundo y captar el sentido que las cosas realmente tienen, captar la ley natural de todo, en vistas de poder enseñarlo a la comunidad, y con ello poder dirigir este mundo, como el capitán de un barco dirige una serie de trozos de madera que dotados de su sentido natural forman un barco.

40 Jos. 95.

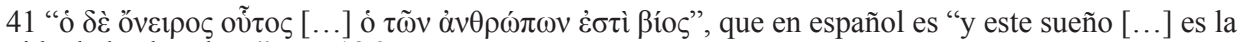
vida de los hombres" Jos. 126. 
M. Díaz-Lisboa. "Filón de Alejandría: consideraciones filosófo-políticas en torno a José (patriarca) y la ley de la naturaleza" en Palabra y Razón. Revista de Teología, Filosofía y Ciencias de la Religión. $\mathrm{N}^{\circ} 17$ Julio 2020, pp 26-43 https://doi.org/10.29035/pyr.17.26

Con todo el trabajo anterior espero haber dejado en claro al menos tres postulados. (1) Que el desarrollo de filosofía política filoniana no se articula teniendo como base una propuesta anti romana, sino más bien, como muchos en la actualidad han demostrado, hunde sus raíces en una cosmovisión universalista del habitar este mundo, donde cada ser humano es parte de esta gran polis, y con ello como derivado, que cualquier crítica dura que presenten los escritos de nuestro autor, no obedecen a un odio general, sino que más bien a uno específico, dirigido a determinadas autoridades de cualquier orden, judíos, griegos o romanos; (2) que la figura de José el patriarca no debe ser utilizada como apoyo para sustentar la tesis anterior, pues como vimos, su vida se desarrolla más bien como un ideal del hombre político que, conociendo la ley de la naturaleza, puede enseñar las virtudes de un sabio a la comunidad, y (3) por último, relacionado con lo anterior, que la relación de José con la ley natural es tan estrecha en su función política como intermediario entre lo divino y lo humano, que parece incluso desconcertante que en magnas obras que estudien la ley natural, como las anteriormente citadas de Martens y Najman, casi ninguna realice al menos un comentario de como se relaciona esta ley con José, la cual, como vimos en el propio texto, es aquella que eligió a José para conocer las artes políticas, lo instruyó en la rama de la ética que es la política y en específico lo seleccionó para ser experto en la micropolítica de la casa del eunuco y en la prisión, y que posteriormente lo llevó a interpretar este sueño que es la realidad, para dotarlo de la misma razón universal que esta inmerso en todo, pero que debe ser desvelado por este intermediario político.

Por último y para no ser desleal con el propio Filón, José no es el mayor intermediario, este puesto será solo ocupado por Moisés, quien muchas veces incluso se identifica con el Logos; por lo cual, siguiendo a Filón

José montó en el segundo de los carros del rey, por la siguiente razón. El hombre político ocupa el segundo lugar tras el rey, pues ni es una persona privada, ni es el rey, sino que participa de los dos extremos, siendo más importante que la persona privada y menor que el rey en poder autoritario. Tiene al pueblo como su rey y su misión es servirle con una fe limpia y pura. (Jos. 148)

Moisés será el verdadero rey, que no solo seguirá la ley natural, sino que de ella hará una copia, Moisés es quien realmente espera en el existente Dios, es el ideal sacerdote y profeta que otorgará la perfecta legislación para el judaísmo (la copia de la ley natural) y para la totalidad de seres 
M. Díaz-Lisboa. "Filón de Alejandría: consideraciones filosófo-políticas en torno a José (patriarca) y la ley de la naturaleza" en Palabra y Razón. Revista de Teología, Filosofía y Ciencias de la Religión. № 17 Julio 2020, pp 26-43 https://doi.org/10.29035/pyr.17.26

humanos. Es Moisés, a quien Filón atribuye, ser el más perfecto de los hombres (Mos. I, 1), el mejor rey, legislador y sacerdote (Mos. II, 187). 
